\title{
Transmission electron microscopy structure and platinum-like temperature coefficient of resistance in a ruthenate-based thick film resistor with copper oxide
}

\author{
J. C. Jiang ${ }^{\text {a) }}$ \\ Department of Materials Science and Engineering, The University of Michigan, Ann Arbor, Michigan 48109
}

Gary M. Crosbie ${ }^{\text {b) }}$

Ford Motor Company, 20000 Rotunda Drive, MD 3182 SRL Bldg., Dearborn, Michigan 48121-2053

W. Tian

Department of Materials Science and Engineering, The University of Michigan, Ann Arbor, Michigan 48109

K. K. Cameron ${ }^{\mathrm{c})}$

Ford Motor Company, 20000 Rotunda Drive, Dearborn, Michigan 48121-2053

X. Q. Pan

Department of Materials Science and Engineering, The University of Michigan, Ann Arbor, Michigan 48109

(Received 17 November 1999; accepted for publication 20 April 2000)

As an alternative to thin-film platinum temperature sensor elements, thick film resistor ones are of interest for circuits which can withstand a near-engine environment. From a pyrochlore paste (DuPont 5091D), a close match is obtained (after firing) to the positive temperature coefficient of resistance (TCR) of Pt. Within the glassy matrix during $850^{\circ} \mathrm{C}$ firing, needle-like $\mathrm{RuO}_{2}$ grains grow by a mechanism consistent with periodic bond chain theory. The acicular growth habit is attributed to a $\mathrm{Cu}_{2} \mathrm{O}$ additive, which is assumed to oxidize upon firing. The needles provide direct paths for metallic conduction and a characteristic positive TCR to the thick film in spite of having a low $\mathrm{RuO}_{2}$ volume fraction. (C) 2000 American Institute of Physics. [S0021-8979(00)08414-0]

\section{INTRODUCTION}

Within the growing palette of thick film resistors, ${ }^{1}$ ones with platinum-like temperature coefficients of resistance (TCR) are of particular interest for automotive underhood applications. Not only can they be integrated in the same process for compact, multilayer, heat resisting circuitry, but they also can simplify temperature output linearization.

For the resistive temperature detection (RTD) thermometry applications, a large positive TCR is required, which is opposite to the goal of previous process-structure-property studies $^{2,3}$ of low TCR resistors. Although fine Pt powders can be prepared as sinterable thick film pastes, such pastes require higher temperatures than normal $850^{\circ} \mathrm{C}$ firing and designs with extremely high aspect ratio serpentines (or a thin film method), due to a low sheet resistance. Although PTCR (positive TCR) thick films have been prepared ${ }^{4}$ from non-noble pure metals (such as $\mathrm{Ni}$ ) under protective atmospheres, they are subject to resistance drift due to oxidation in service.

For thick film resistors (TFR) with positive TCRs that are based on electronic conduction in air-stable oxides, the means are only described in a few citations. This literature

\footnotetext{
${ }^{a}$ Current address: Mechanical Engineering Dept., Louisiana State University, Baton Rouge, LA 70803-6413.

${ }^{b}$ Author to whom correspondence should be addressed; electronic mail: gcrosbie@ford.com

${ }^{c}$ Current address: Mechanical Engineering Dept., Stanford University, Bldg. 530, Stanford, CA 94305-3030.
}

points to three efforts, one ${ }^{5}$ with $\mathrm{Ca}-\mathrm{Cu}-\mathrm{Ru}-\mathrm{O}$ compounds (with TCRs near $2000 \mathrm{ppm} / \mathrm{K}$ ) and a second one ${ }^{6-9}$ with $\mathrm{Cu}_{2} \mathrm{O}$ added to a $\mathrm{Pb}_{2} \mathrm{Ru}_{2} \mathrm{O}_{6.5}$-based pyrochlores (with some secant TCRs above $3000 \mathrm{ppm} / \mathrm{K}$ ). The latter ones correspond to a recently introduced, conventionally firing PTCR paste, 5091D, which has no platinum. A third effort, ${ }^{10}$ with addition of copper oxides to a $\mathrm{RuO}_{2}$-based TFR, increases the TCR, but only to near $1000 \mathrm{ppm} / \mathrm{K}$.

In support of manufacturing circuits with a high TCR paste, some knowledge of processing-microstructure relationships is useful to aid in understanding the best ways to design, print, and fire the material. As before with the low TCR resistors, ${ }^{2}$ the investigation provides another interesting example of nanoscale composite electrical resistivity, as enhanced with a phase transformation observed during firing.

\section{EXPERIMENT}

Four probe layout designs were used with two internal probes of the self-same resistor material to exclude end effects. The present design has a smaller width $(0.254 \mathrm{~cm})$ and higher aspect ratio (8:1) than that used in low TCR resistor work (in Ref. 2, Fig. 4). Also provided were x-ray diffraction (XRD) pads $(1 \mathrm{~cm} \times 1.5 \mathrm{~cm})$, which were also used for transmission electron microscopy (TEM). Quantities were sufficient to allow estimation of electrical property distributions.

The substrates used were $96 \%$ alumina, Coors AD-96 substrates of $0.635 \mathrm{~mm}$ thickness and size $86 \times 166 \mathrm{~mm}$, with four images each per plate. The substrates were washed and dried prior to conductor printing. 
TABLE I. Resistance vs temperature values as fitted to the three parameters of Eq. (1).

\begin{tabular}{cccc}
\hline \hline & & $\begin{array}{c}\text { Central } \\
\text { (inner } \\
\text { probes) }\end{array}$ & $\begin{array}{c}\text { Platinum } \\
\text { comparison }\end{array}$ \\
$n$ & $\begin{array}{c}\text { Unit } \\
\text { (count) }\end{array}$ & 52 & 18 \\
\hline$R_{0} \pm \sigma_{R}$ & $(\Omega)$ & $96.66 \pm 9.09$ & $18.39 \pm 0.40$ \\
$\alpha \pm \sigma_{\alpha}$ & $(\mathrm{ppm} / \mathrm{K})$ & $3796 \pm 36$ & $3798 \pm 12$ \\
$\beta \pm \sigma_{\beta}$ & $\left(\mathrm{ppm} / \mathrm{K}^{2}\right)$ & $-0.821 \pm 0.644$ & $-0.99 \pm 0.21$ \\
\hline \hline
\end{tabular}

The conductor used was DuPont 7474F Ag-Pd alloy (nominally, 3Ag:1Pd) for low TCR interconnects. It is a physical mixture of fine $\mathrm{Ag}$ and $\mathrm{Pd}$ with some $\mathrm{Bi}_{2} \mathrm{O}_{3}$, as determined by XRD. As it is fired at $850^{\circ} \mathrm{C}$ for $10 \mathrm{~min}$, it alloys to form a single phase of intermediate lattice constant.

The sheet resistance of the resistor paste used (DuPont 5091D, Lot IFH135) was nominally $10 \Omega /$ sq. As a paste (glass frit in an organic vehicle), its XRD is that of a pyrochlore indexed by $\mathrm{Pb}_{2} \mathrm{Ru}_{2} \mathrm{O}_{6.5}$ with $\mathrm{ZrSiO}_{4}$ and $\mathrm{Cu}_{2} \mathrm{O}$, with a broad background from glass. The paste was printed with a 325 mesh stainless steel screen with a $0.2 \mathrm{~mm}$ emulsion to an as-dried thickness of 24.3-25.7 $\mu \mathrm{m}$.

A belt furnace thermal cycle was used that closely approximates the standard DuPont cycle with $\sim 10$ min at peak temperature of $850^{\circ} \mathrm{C}$. After firing, the resistor thickness decreased to $14.9-16.3 \mu \mathrm{m}$ (average $15.6 \mu \mathrm{m}$ ). No $\mathrm{Cu}_{2} \mathrm{O}$ was detected by XRD.

For resistance measurements, test boards were mounted in a temperature-controlled chamber (Model 4248B, Saunders Associates, Scottsdale, AZ) and held for a minimum of 5 min with the chamber within $1{ }^{\circ} \mathrm{C}$ of target temperatures, in sequence: $25,-40,125,140,100$, and $150^{\circ} \mathrm{C}$. Four probe measurements were made using a system voltmeter. Fitting was done with Microsoft Excel to a quadratic TCR model, commonly used with Pt RTDs.

Cross-section and plan-view samples were prepared for TEM studies by cutting, mechanical grinding, polishing, dimpling, and low-angle Ar-ion milling to perforation. The survey studies were conducted with a JEOL 2000FX analytical electron microscope, operating at $200 \mathrm{kV}$, equipped with an x-ray energy-dispersive spectrometer (EDS). Highresolution TEM (HRTEM) was carried out with a JEOL $4000 \mathrm{EX}$ electron microscope operated at $400 \mathrm{kV}$ (point resolution $0.17 \mathrm{~nm}$ ) and equipped with a Gatan image Filter (GIF) system. HRTEM images were digitally recorded using a slow scan CCD camera.

\section{RESULTS}

\section{A. Resistance and resistivity}

Table I shows the $R(T)$ data for the central interprobe section fit to a quadratic TCR model, as is typically used for platinum based RTDs:

$$
R(T)=R_{0}\left(1+\alpha T+\beta T^{2}\right),
$$

where $T$ is temperature in ${ }^{\circ} \mathrm{C}$ and $R_{0}$ denotes resistance at $0{ }^{\circ} \mathrm{C}$. For this quadratic fitting of individual thick film resis-
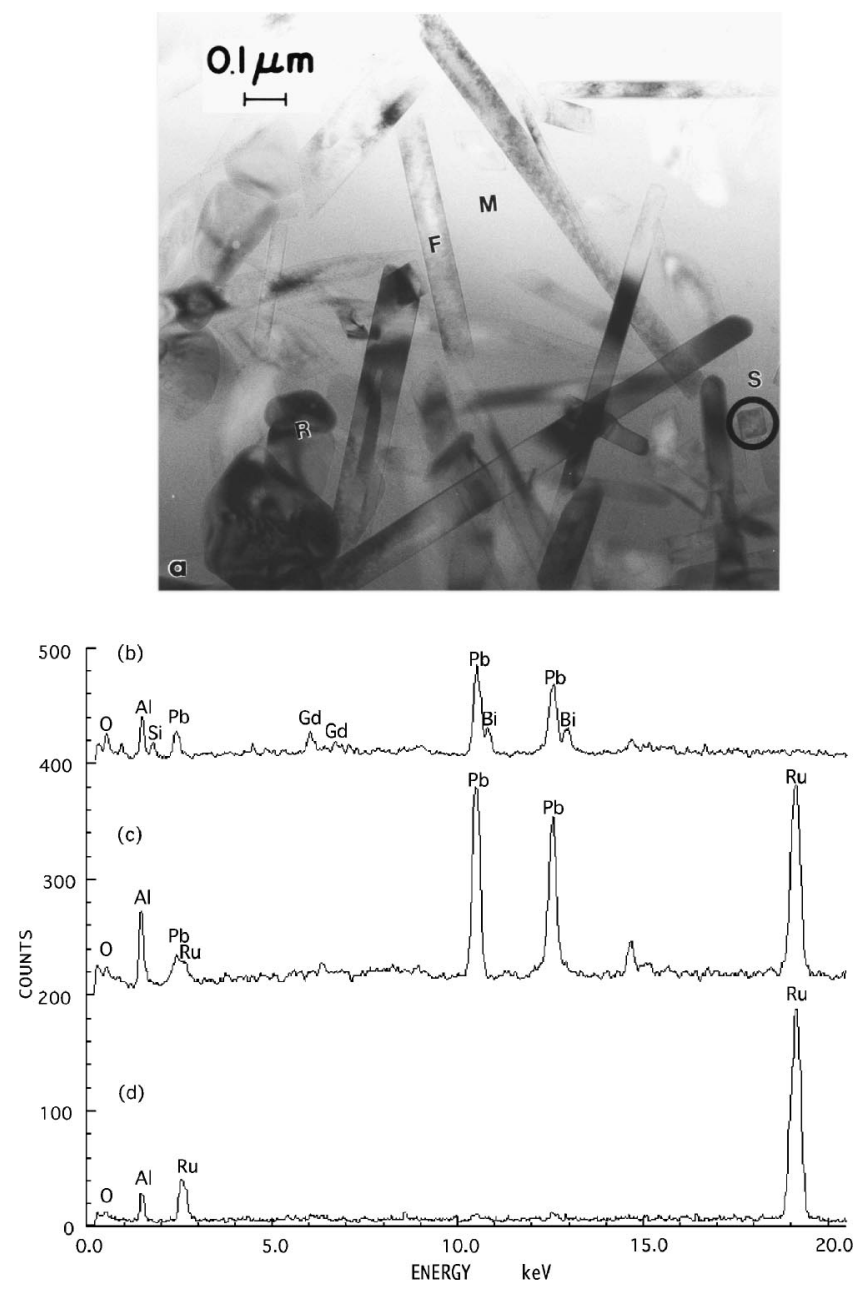

FIG. 1. (a) Bright-field TEM micrograph showing fiber structures. (b), (c), and (d) are EDS spectra from the matrix (region M), equiaxed particles (R) and a fiber (F), respectively, in micrograph (a). A cross section is circled at (S).

tances [to the $R(T)$ of Eq. (1) at six temperatures from $-40^{\circ} \mathrm{C}$ to $\left.+150^{\circ} \mathrm{C}\right]$, typical Pearson correlation coefficients, $R^{2}$ (in the usual statistical notation), are about 0.999 98. (Straight-line fitting typically gives lower correlation $R^{2}$ values, about 0.9999 .) The platinum comparison in Table I is for thin film temperature sensing elements. In statistical $t$ tests, neither the mean of the linear coefficient, $\alpha$, nor the quadratic coefficient, $\beta$, of the thick film resistors differed significantly (95\% level) from those of the Pt elements.

Calculated from the average fired thickness of $15.6 \mu \mathrm{m}$, the resistivities of the thick film material in the central sections are: $0.0206 \pm 0.0019 \Omega \mathrm{cm}$ at $25^{\circ} \mathrm{C}$ and 0.0292 $\pm 0.0027 \Omega \mathrm{cm}$ at $150{ }^{\circ} \mathrm{C}$.

\section{B. Transmission electron microscopy characterization}

Figure 1(a) is a bright-field TEM micrograph showing a representative microstructure of the ruthenate-based thick film resistor. Equiaxed particles and elongated grains (needles or fibers) are embedded in a matrix material ob- 


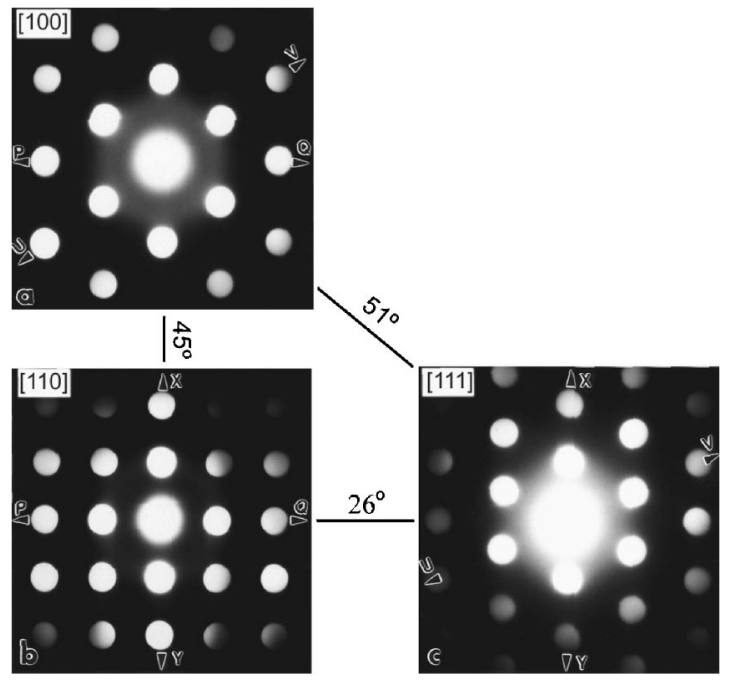

FIG. 2. Microelectron diffraction patterns taken from the same fiber $(\mathrm{F})$. Images (a), (b), and (c), respectively, correspond to the [100], [110], and [111] zone electron diffraction patterns of $\mathrm{RuO}_{2}$.

served in Fig. 1(a). The width of most fibers is in the range from 10 to $80 \mathrm{~nm}$, based on the examination of numerous micrographs from various areas.

The compositions of the matrix, equiaxed particles, and fibers in the specimen were determined by EDS analysis. Figures 1(b)-1(d) are EDS spectra taken from the matrix area $(\mathrm{M})$, equiaxed particle $(\mathrm{R})$, and fiber (F) in Fig. 1(a), respectively. An EDS spectrum taken from the matrix shows the presence of $\mathrm{Pb}, \mathrm{Bi}, \mathrm{Gd}, \mathrm{Al}, \mathrm{Si}$, and $\mathrm{O}$. The matrix is amorphous based on the electron diffraction analysis. EDS spectra taken from equiaxed particles show the presence of $\mathrm{Ru}, \mathrm{Pb}, \mathrm{O}$, and $\mathrm{Al}$. These equiaxed particles are, therefore, identified as the $\mathrm{Pb}_{2} \mathrm{Ru}_{2} \mathrm{O}_{6.5}$ phase. The EDS spectrum taken from the fibers shows one intense Ru peak and other peaks from $\mathrm{Al}$ and $\mathrm{O}$, which together indicate that the fiber is a Ru-rich compound.

In order to determine the crystallographic structure of the fibers in ruthenate-based thick film resistors, microbeam electron diffraction analysis was conducted. Figures 2(a)2(c) are microbeam electron diffraction patterns from the same fiber for three different zone axes. Figure 2(b) was obtained by tilting the electron diffraction pattern of Fig. 2(a) around the PQ axis by $45^{\circ}$. Similarly, Fig. 2(c) was obtained by tilting the electron diffraction pattern of Fig. 2(a) around the UV axis by $51^{\circ}$. The angle between the two zone axes shown in Figs. 2(b) and 2(c) is $26^{\circ}$. That is to say, by tilting the electron diffraction pattern of Fig. 2(b) around the XY axis by $26^{\circ}$, we can obtain the diffraction pattern of Fig. 2(c). The angular relationship between the three zone axes is illustrated by the triangle in Fig. 2. Based on the diffraction pattern calculations, Figs. 2(a)-2(c) are the [100], [110], and [111] zone electron diffraction patterns, respectively, of $\mathrm{RuO}_{2}$. Therefore, the crystal structure of the fiber is identified as the structure of $\mathrm{RuO}_{2}$.

Figure 3(a) is a high-resolution TEM image of the profile of a part of a fiber that is $12 \mathrm{~nm}$ in width and about 200nm in length. Its Fourier transformation [Fig. 3(b)] shows the [111] zone diffraction pattern of $\mathrm{RuO}_{2}$. The planes with a
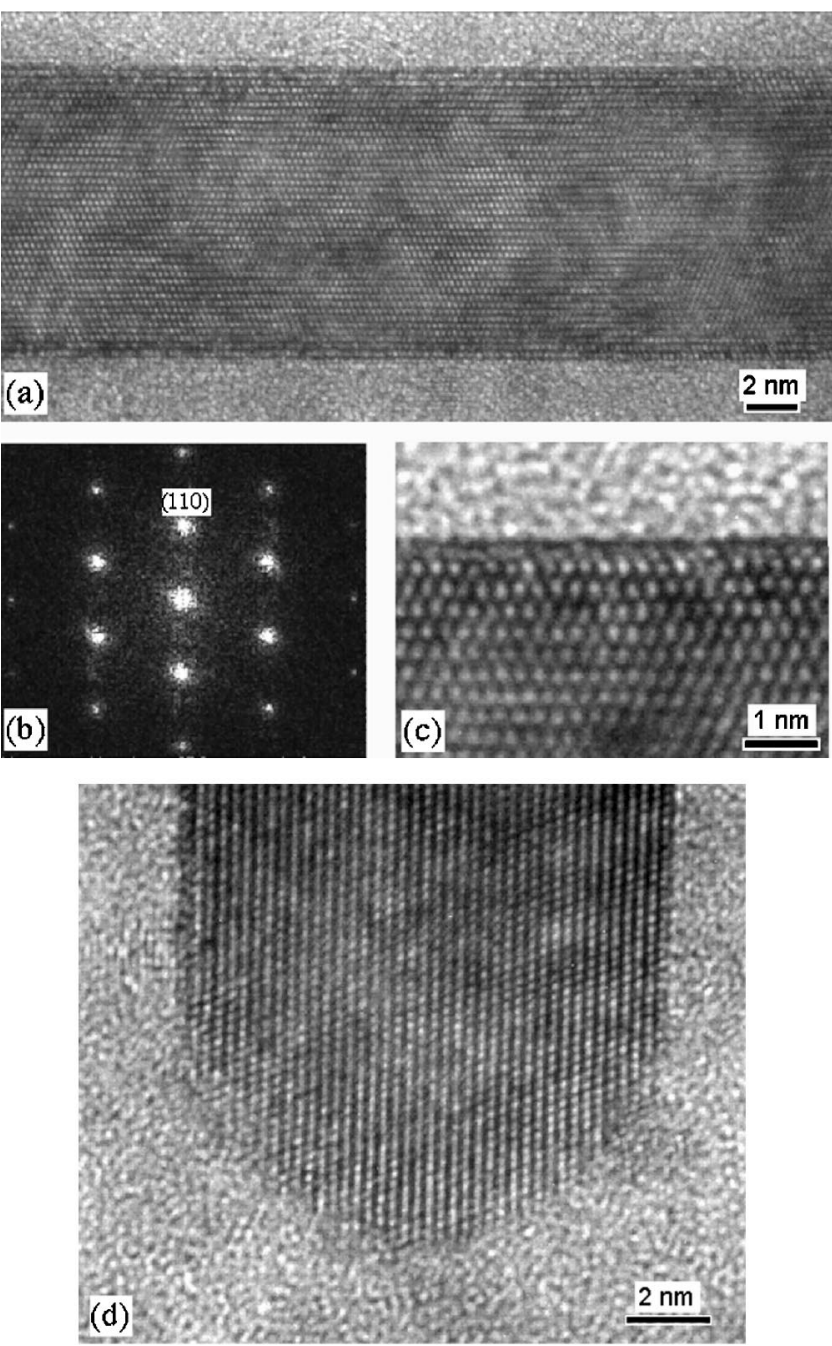

FIG. 3. (a) HRTEM micrograph taken from a part of a fiber showing the profile image; (b) Fourier transformation of (a); (c) HRTEM image showing the atomic structure the fiber/matrix interface; and (d) HRTEM image of the head of the fiber showing a rounded-ended cap morphology.

d spacing of $3.2 \AA$ and with an orientation that is parallel to the long axis of the fiber are (110) planes of $\mathrm{RuO}_{2}$. The interface between the fiber and amorphous matrix are found to be atomically flat. Over the entire fiber, no steps were found on the profile of the fiber. Figure 3(c) is a highresolution TEM image of the fiber/matrix interface. The image characteristics of the outermost monolayer of the fiber are different from those of the inner layers.

Figure 3(d) is a HRTEM image of the end of a fiber. This image shows a round ended, rough interface, consisting of ledges and steps. In order to image high quality highresolution TEM micrographs, it is known that the area of the specimen for imaging is preferred to be less than $10 \mathrm{~nm}$ thick. The thin fiber [in Fig. 3(a)] keeps the same width over the $200 \mathrm{~nm}$ length and lies parallel within this thin TEM specimen. Therefore, the round-end-cap morphology shown in Fig. 3(d) does represents the profile of the fiber end (rather than the end of a section). Accordingly, the fibers in these ruthenate-based thick film resistors are concluded to have a nearly spherical cap morphology. This conclusion can also 
(a)

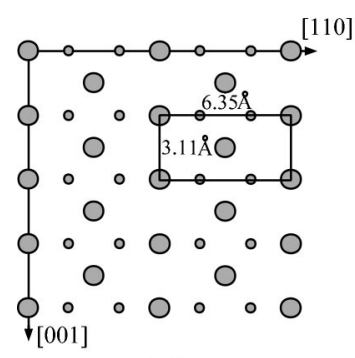

(c)

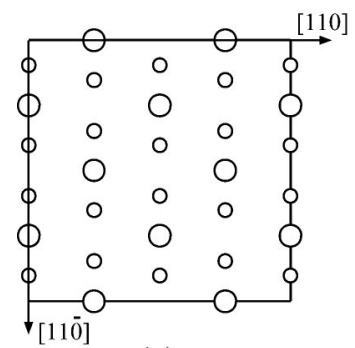

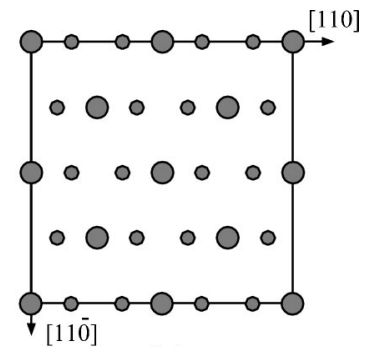

(b)

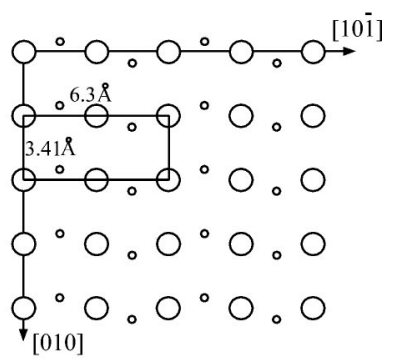

(d)
FIG. 4. Diagrams (a) and (b) show the atomic distribution of $\mathrm{RuO}_{2}$ on (001) (at $z=0)$ and (002) (at $z=1 / 2$ ) planes. Large and small circles represent $\mathrm{Ru}$ and $\mathrm{O}$ atoms, respectively, (c) shows the atomic arrangement of the (110) plane consisting of $\mathrm{Ru}$ and $\mathrm{O}$ atoms, (d) shows the atomic arrangement of (111) plane of $\mathrm{CuO}$, in which large and small circles represent $\mathrm{Cu}$ and $\mathrm{O}$ atoms, respectively.

be supported by the additional fiber end images shown in Fig. 1(a).

Based on the morphology of the $\mathrm{RuO}_{2}$ square crosssection particle (marked by letter " $S$ ') in Fig. 1(a), the cross-sectional shape of the fibers can be deduced to be a square. The edges of the square section are inferred to be parallel to the [110] and [1 10$]$ directions of $\mathrm{RuO}_{2}$. Therefore, the three-dimensional morphology of the fiber is a square pole with a long axis parallel to the [001] axis of $\mathrm{RuO}_{2}$ and with faces parallel to the (110) and (1 $\left.\overline{1} 0\right)$ planes.

\section{DISCUSSION}

The needle-like microstructure differs from the equiaxed pyrochlore particles of low TCR pastes that were previously studied. ${ }^{2,3}$ This acicular structure shifts the larger contribution for electrical resistance in the composite to the metallike phase and, therefore, produces a highly positive TCR.

\section{A. Microscopic composition and crystallography}

The growth mechanism of the $\mathrm{RuO}_{2}$ fibers can be understood using periodic bond chain (PBC) theory. ${ }^{11}$ It is known ${ }^{12}$ that $\mathrm{RuO}_{2}$ is a tetragonal phase with the space group $\mathrm{P} 4_{2} / \mathrm{mnm}$ and lattice parameters: $a=4.49$ and $c=3.11 \AA$. The PBC vectors in $\mathrm{RuO}_{2}$ can be considered to lie along the [110], [1 10$]$, and [001] directions. The $\mathrm{Ru}-\mathrm{O}$ chain on the (002) plane is rotated $90^{\circ}$ around the [001] axis with respect to that on the adjacent (001) planes, as shown in Figs. 4(a) and 4(b). Specifically, the $\mathrm{Ru}-\mathrm{O}$ chain on the (002) plane is oriented along the [110] direction of $\mathrm{RuO}_{2}$, whereas that on the $(001)$ is oriented along the [1 $\overline{1} 0]$ direction. Therefore, the (001) interface is rough and has many steps naturally provided which are attachment/growth sites to adsorb the adatoms. The growth in the [001] direction will be governed by the mass transport through the glass matrix. (By the time the thick film composite reaches the $850^{\circ} \mathrm{C}$ firing temperature, the $\mathrm{Ru}$-containing oxide particles are entirely encapsulated within a glassy matrix. Consequently, no gas phase is adjacent to the growing needles in which any volatile species might move.) In contrast, the (110) interface consisting of $\mathrm{Ru}$ and $\mathrm{O}$ atoms is a flat plane and is close packed, as illustrated in Fig. 4(c). The (110) plane of $\mathrm{RuO}_{2}$, together with its equivalent (1 $\overline{1} 0),(\overline{1} 10)$, and ( $\overline{1} \overline{1} 0)$ planes, form four flat interfaces between the fiber and the amorphous matrix. There are no attachment/growth sites in such a flat interface to permit adsorption of adatoms. The growth of the flat interface along the [110] and [1 $\overline{1} 0]$ directions is governed by a layerto-layer two-dimensional plane growth mode, which is controlled by the interfacial nucleation and diffusion. Consequently, the growth rate in the [001] direction (length) of the fiber is much higher than that in [110] direction (width).

$\mathrm{X}$-ray powder diffraction pattern analyses show that the small amount of $\mathrm{Cu}_{2} \mathrm{O}$ phase existing in the ruthenate-based resistor pastes disappears after firing. It may be presumed that, upon firing, the $\mathrm{Cu}_{2} \mathrm{O}$ phase in the precursor paste oxidizes to $\mathrm{CuO}$, which then dissolves in the glass. Figure 4(d)

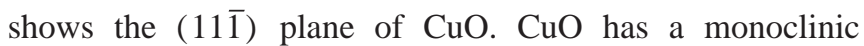
structure $^{13}$ with lattice parameters: $a_{\mathrm{CuO}}=4.653 \AA, b_{\mathrm{CuO}}$ $=3.41 \AA, c_{\mathrm{CuO}}=5.108 \AA$, and $\beta=99^{\circ} 29^{\prime}$. The size of the

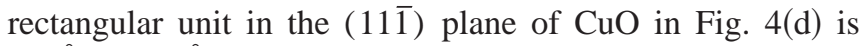
$6.3 \AA \times 3.41 \AA$. These values are close in size to that of the rectangular unit in the (110) plane of $\mathrm{RuO}_{2}$ at $6.35 \AA$

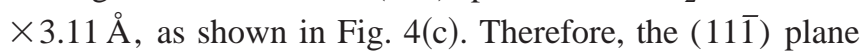
of $\mathrm{CuO}$ is nearly lattice matched to the (110) plane of $\mathrm{RuO}_{2}$ for a specific orientation relationship of $\mathrm{RuO}_{2}-[001] \| \mathrm{CuO}-[010]$ and $\mathrm{RuO}_{2}-[110] \| \mathrm{CuO}-[10 \overline{1}]$. It is possible that during the growth of the fibers, (110) flat inter-

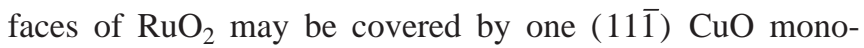
layer. As shown in Fig. 3(c), structural differences between the outermost monolayer and the inner layers of the fiber near the interface, may be considered as support of this model. The interfacial $\mathrm{CuO}$ monolayer would slow the growth of the $\mathrm{RuO}_{2}$ fiber along the [110] and [1 10$]$ directions, but have little influence on the growth in the [110] direction.

\section{B. Resistance and resistivity}

The similarity to $\mathrm{Pt}$ of the fitted parameters (Table I) of the quadratic $\left(T, T^{2}\right)$ model of Eq. (1) is of practical importance as this suggests the possibility of direct substitution with existing circuit calibrations.

In prior work ${ }^{2}$ with near-zero TCR resistors, it had been shown that a $(T, 1 / T)$-fit was a better match to experimental data. The physical basis of the $(T, 1 / T)$-fit is the two-phase resistance model. ${ }^{14}$ In the present work, the high aspect ratios of the $\mathrm{RuO}_{2}$ needles provide straight metallic conduction bypass routes to any parallel routes through nonreacted, equiaxed $\mathrm{Pb}_{2} \mathrm{Ru}_{2} \mathrm{O}_{6.5}$ particles and glass interfaces. Because of the high aspect ratios, the needles make the resistance 
contribution in the overall composite from interparticle tunneling barriers an insignificant share of the measured resistance, as observed down to cryogenic temperatures. ${ }^{6}$ Thus, only the metallic terms in Eq. (8) of Ref. 14 are included, which correspond to the constant and linear terms in the quadratic fit. The quadratic term is small but concave downward. Force fitting of the two phase resistance model ${ }^{14}$ gives a small, but negative, electrostatic charging energy, which is physically unreasonable.

\section{Role of morphology on TCR}

The observed needle-like microstructure differs from the equiaxed ones of low-TCR ruthenate ${ }^{2,3}$ thick films that remain ruthenates. The transformation to a needle-like morphology is essential to obtain the metal-like magnitudes of positive TCR.

In the present PTCR material, some of the ruthenate decomposes to $\mathrm{RuO}_{2}$ and $\mathrm{PbO}$ (which dissolves in the glass). The decomposition of the ruthenate depends on glass chemistry, ${ }^{8,15}$ and is enhanced by a lower initial concentration of $\mathrm{PbO}$ in the glass frit. ${ }^{16}$ With the transformation, elongated thin plates of $\mathrm{RuO}_{2}$ have been observed..$^{16}$ It was noted (Column 3, Lines 49-50 of Ref. 8) that the high TCRs are not achieved for the compositions that are produced from $\mathrm{RuO}_{2}$ powders. Due to surface energy considerations, $\mathrm{RuO}_{2}$ powders cannot "coarsen" into high aspect ratio shapes. With the transformation from ruthenate to $\mathrm{RuO}_{2}$ (plus dissolved $\mathrm{PbO}$ ), high specific surface area fiber growth becomes possible.

Experimentally, the addition of copper as oxide is known (Table VI, Ref. 9) to be critical to obtaining the higher TCRs. The explanation previously given ("interaction of the conductive phase with the glassy matrix" $)^{6}$ is rather vague. In the present samples, $\mathrm{Cu}_{2} \mathrm{O}$ (detected by XRD in the paste mixture) is oxidized during air firing to $\mathrm{CuO}$, which dissolves in the glassy matrix. As described above, $\mathrm{CuO}$ has a specific crystallographic relationship which assists in the growth of the $\mathrm{RuO}_{2}$ in a fiber morphology. In this fiber shape, the composite conductivity is that of the long axis of the needles, the $\mathrm{RuO}_{2}$ [001] direction. Columns of atoms of $\mathrm{Ru}$ are then aligned to provide a metal-like conduction mechanism which leads to a highly positive, metal-like temperature coefficient of resistance.

\section{CONCLUSIONS}

The positive TCR thick film resistor differs from low TCR pastes, in that the DuPont 5091 pyrochlore in the paste partially transforms during firing to needle-like $\mathrm{RuO}_{2}$ grains, rather than only coarsening.
Lattice-matched $\mathrm{CuO}$ monolayers on the (110) $\mathrm{RuO}_{2}$ surfaces may help form the atomistically flat needle faces and lead to such high aspect ratio needles. High resolution TEM shows that the growth ends are rounded, consistent with periodic bond chain theory.

The close match of TCR may allow substitution for Ptbased thick films, with lower cost (due to the low volume fraction of needles needed for continuous path formation) and better oxidation resistance than with thick film resistors based on non-noble metals, such as Ni.

\section{ACKNOWLEDGMENTS}

The authors would like to thank Stacie A. Fenner and David Benson of Ford Research Laboratory for supporting XRD and XRF; Matt T. Hayes for work in an initial PTCR study; and Ford/Visteon contributors: Dave Smith, Russ Haeberle, Randy Hume, Marisa Kurpiewski, and Thuong Pham. Technical support and advice are acknowledged from Rudy Bacher and Al Walker of DuPont. The work at the University of Michigan was supported by the National Science Foundation through Grant No. DMR-9875405 and the College of Engineering at the University of Michigan.

${ }^{1}$ T. Pfeiffer and R. J. Bouchard, Ceram. Mater. 33, 405 (1993).

${ }^{2}$ G. M. Crosbie, F. Johnson, and W. Trela, J. Appl. Phys. 84, 2913 (1998).

${ }^{3}$ F. Johnson, G. M. Crosbie, and W. T. Donlon, J. Mater. Sci.: Mater. Electron. 8, 29 (1997)

${ }^{4}$ H. Arima, in Thick Film Sensors, edited by M. Prudenziati (Handbook of Sensors and Actuators (Elsevier, Amsterdam 1994), Vol. 1, pp. 127-150.

${ }^{5}$ H.-G. Burckhardt, F. Gora, K.-H. Guldner, J. Dehoust, C. Modes, J. Schmidt, R. Kiemel, and S. Kemmler-Sack, U.S. Patent No. 5,244,601 (14 September 1993).

${ }^{6}$ J. Hormadaly, S. J. Horowitz, J. R. Larry, and P. O'Callaghan, in MCMC/Mixed Technologies and Thick Film Sensors, edited by W. K. Jones et al. (NATO ASI Series 3, No. 2 (Kluwer Academic, Dordrecht, 1995), pp. 259-265.

${ }^{7}$ J. Hormadaly, J. R. Larry, and S. Mergui, in Multichip Modules with Integrated Sensors, edited by W. Kinzy Jones and Gábor Harsányi (NATO ASI Series 3, No. 16 (Kluwer Academic, Dordrecht, 1996), pp. $163-172$.

${ }^{8}$ J. Hormadaly, U.S. Patent No. 4,906,406 (6 March 1990).

${ }^{9}$ J. Hormadaly, U.S. Patent No. 4,961,999 (9 October 1990).

${ }^{10}$ T. Yamaguchi and K. Tanai, Proc. SPIE 1847, 463 (1992).

${ }^{11}$ P. Hartman and W. G. Perdok, Acta Crystallogr. 8, 49 (1955).

${ }^{12}$ V. M. Goldschmidt, Skrifter Norske Videnskaps-Akad. Oslo I. Mat.Naturv. K1. No. 1 (1926).

${ }^{13}$ G. Tunell, E. Posnjak, and C. J. Ksanda, J. Wash. Acad. Sci. 23, 195 (1933).

${ }^{14}$ G. E. Pike and C. H. Seager, J. Appl. Phys. 48, 5152 (1977).

${ }^{15}$ A. T. Walker, L. A. Silverman, K. W. Hang, T. Pfeiffer, V. P. Siuta, L. H. Slack, and R. J. Bouchard, Proc. SPIE 2105, 695 (1993).

${ }^{16}$ K. Adachi and H. Kuno, J. Am. Ceram. Soc. 80, 1055 (1997). 